\title{
Sobre el Hábeas Data y su tutela*
}

\section{Domingo García Belaunde}

Mi intervención estaba dirigida al Hábeas Data y al Amparo en el Perú. Pero como mi amigo Francisco J. Eguiguren ha expuesto con mucha solvencia sobre estos temas, en especial sobre los antecedentes y desarrollo del Hábeas Data, he optado por hacer un planteo distinto, que privilegia ciertos aspectos doctrinarios, y que me parece de interés.

Mi exposición tendrá dos partes. Una genérica, un poco teórica y debatible sobre lo que es el Hábeas Data y los problemas teóricos que suscita. Y una parte final más breve, en que haré una pequeña referencia al debate político que hubo sobre el Hábeas Data en el Perú, punto que el Dr. Eguiguren no ha tocado, permitiéndome hacer este ex cursus.

Pienso que la problemática que vamos a abordar ahora, está relacionada con lo que hemos discutido y con las cosas que se han dicho. Ustedes me van a disculpar que tome posición en este tema, porque a través de estas jornadas, de estos días, hemos hablado de muchas cosas relacionadas con el Hábeas Data, y hay muchas más que han quedado sueltas. Y quizá alguien debía hacer un resumen o un replanteo; no digo que yo sea el indicado, ni que lo que yo haga sea lo más acertado, pero por lo menos voy a intentarlo. En todo caso, todo está sujeto a ratificación, rectificación o aplauso si es que hubiese algún entusiasta de la idea.

Creo que lo primero que tenemos que abordar (naturalmente esta es una posición personal que les ruego que acepten como tal) es el

* La primera versión de este texto apareció en Ius et Praxis. Derecho en la región, núm. 3, Talca, primer semestre de 1997, con errores y omisiones. Se publica nuevamente revisado y corregido, respetando las características de una exposición oral. 
problema de la terminología; o sea, qué término emplear. Acá tenemos que remontarnos a la Revolución francesa y a la influencia que ella ha tenido sobre nosotros, así como la doctrina francesa inicial, a veces directamente, a veces a través de la práctica española. Y es el uso clásico de la palabra "garantía".

Ella en su sentido clásico es un equivalente a lo que hoy conocemos como derecho. Los franceses hablaron de las garantías. ¿Quién no conoce una garantía? El libre tránsito, el libre pensamiento, la libre expresión de ideas, la libertad de prensa; esas eran garantías.

Los revolucionarios franceses se abrazaban emocionados pensando que con la simple proclamación de los derechos, éstos se iban a cumplir. Y no previeron que en el fondo los derechos, tal como estaban enunciados ahí, generaban confusión porque unas veces usaban la palabra garantía y otras de derecho. No fueron concientes que todo enunciado referido a la persona necesitaba un instrumento de protección. Y es que el Derecho Procesal en esa época no existía; va a existir mucho más tarde. Entonces hay una confusión que se refleja en los textos latinoamericanos, sobre todo en el siglo XIX y bien entrado el siglo XX, y vigente en algunos, como es el caso de México; Perú y Argentina hasta hace poco, en el cual la garantía es igual que derecho. Y se habla de derechos y garantías en forma sinónima, como si fuesen equivalentes.

Sin embargo, los constitucionalistas llamaron la atención, ya a principios de este siglo, sobre este hecho. Hay una monografía clásica del año 27, en la cual un gran maestro argentino, Carlos Sánchez Viamonte, en su estudio sobre el Hábeas Corpus, dice: No es posible seguir llamando al libre tránsito o al libre pensamiento garantía, porque ellos por sí solos no garantizan nada, necesitan de otro instrumento para garantizarlos. Entonces Sánchez Viamonte en aquella época, cuando el procesalismo científico estaba recién conociéndose y él seguramente lo desconocía aún más, llegó por intuición a la conclusión que el Hábeas Corpus, o sea, el instrumento, era la garantía. ¿De qué? de los derechos que éste protegía; o sea, en su sentido clásico, la libertad de locomoción.

Entonces, hay una primera acepción de la palabra garantía, la clási$\mathrm{ca}$, que tiene imperio casi absoluto en los Estados latinoamericanos, sobre todo en el siglo XIX y en gran parte del siglo XX. Y esta confusión todavía existe en la doctrina, pues se usa garantía como sinónimo de derecho. 
Más adelante, a la altura de los años 50, se empieza a correr traslado del concepto de garantía, o sea el nombre "garantía" se conceptúa como un instrumento de defensa. Y esto se nota claramente en la doctrina latinoamericana, sobre todo en la obra de un gran maestro, amigo de todos nosotros, que es Héctor Fix Zamudio, la cual dice que las garantías son los instrumentos procesales aptos para la defensa de los derechos fundamentales. $\mathrm{O}$ sea, para la concepción reciente, una cosa es el derecho y otra es el instrumento para proteger el ejercicio de ese derecho.

En ese sentido, alguna parte de la doctrina habla de acciones de garantía, y así nuestra Constitución peruana, dando un paso adelante desde una tradición bastante antigua, habla de acciones de garantía. El Hábeas Data está calificado en la Constitución de 1993 como una acción de garantía.

Pero el tercer concepto que aquí nos interesa, es el concepto moderno y científico, en el cual éstos son considerados como procesos. Justamente, en una comisión en la que estamos trabajando en Lima, intentamos estructurar todo esto relativo a la parte procesal, estamos calificando el Hábeas Data como Proceso de Hábeas Data. No acción, sino proceso constitucional, porque la acción es algo abstracto, que sirve para iniciar algo, pues la acción en sí misma no es nada. Entonces, lo primero es ponernos de acuerdo con el concepto.

Parte de la doctrina latinoamericana ya empieza a hablar de procesos constitucionales. A raíz de la Constitución del Brasil, hay muchos autores que han trabajado esos instrumentos, como son el Hábeas Data, la Injuncao, el Mandato de Segurança, etc. Creo que esto habría que tenerlo presente, para saber a qué es a lo que estamos apuntando.

Esto nos lleva al segundo aspecto. Los clásicos derechos fueron enunciados fundamentalmente en las llamadas por los historiadores, revoluciones burguesas del siglo XVIII. Fundamentalmente revoluciones liberales en Estados Unidos y en Francia, cuando fueron declarados los derechos fundamentales del hombre, o los derechos naturales, etc. Luego, esos derechos tienen que ver con una parte fundamental del Derecho Constitucional, pero la parte de la protección instrumental es otra cosa. $\mathrm{Y}$ aunque hay una discusión sobre esto en algunos medios constitucionales, yo me inclino a pensar que la parte instrumental es propia de la Teoría del Proceso, es propia del Derecho Procesal. Y esto debe dar justamente nacimiento a lo que ya está siendo estudiado tímidamente 
por algunos autores, que es el Derecho Procesal Constitucional como una rama del Derecho Procesal, en el entendido que el proceso es uno solo, como lo dicen los mejores procesalistas modernos.

Autores muy acreditados así lo señalan, y no voy a referirme sino solamente a los latinoamericanos como Véscovi por ejemplo, Devis Echandía, o algunos que han estado mucho tiempo en América Latina, como es el caso de Fairén Guillén, quien en un libro publicado en México, señala que el proceso es uno solo, y que el área de aplicación varía. Entonces en el área civil se llama Derecho Procesal Civil, si es penal se llama Derecho Procesal Penal, y así sucesivamente.

Habría así un Derecho Procesal Constitucional. Esto nos serviría para distinguir lo que es el Derecho Constitucional de lo que es el Derecho Procesal Constitucional, que es la parte procesal. Lamentablemente los procesalistas no se preocupan de esta parte procesal constitucional, porque no conocen constitucional. Ese es el problema, o esa es la tragedia. Normalmente todos recibimos una formación civil y penal; entonces el procesalista civil sabe civil y el procesalista penal sabe penal, pero el procesalista constitucional requiere saber constitucional y el procesalista común y corriente, generalmente no lo sabe.

Acá he visto en el plan de estudios de esta Facultad, un programa en el cual se dicta el curso de Derecho Procesal Constitucional, lo cual me parece un avance notable. Deben ser tres o cuatro casos en América Latina; no creo que haya más.

Partiendo de eso, arribamos al tercer punto. ¿Qué hacemos con el Hábeas Data? Cae por su propio peso que el Hábeas Data es una figura procesal para la defensa de determinados derechos, que es propia de la disciplina que algunos conocen, estudian, divulgan, etc., como Derecho Procesal Constitucional. Lo que pasa es que su manejo, su ejercicio es procesal, pero sus fundamentos son constitucionales. Lo cual no impide, que los constitucionalistas lo estudien y practiquen.

Por tanto el Hábeas Data, al ser una acción o instrumento típicamente procesal, debe ser enmarcado dentro de lo que es la Teoría del Proceso, y en consecuencia definido conforme a ella, y no a lo que querramos nosotros como constitucionalistas.

Pero si seguimos adelante naturalmente viene la otra pregunta. ¿¿Qué hacemos con esta figura procesal? Antes que nada ¿tiene que ser una figura procesal? Bueno, eso depende del legislador, quien las crea, o en su defecto del constituyente. No hace falta que se llame expresamente 
Hábeas Data; en el caso argentino no existe ese nombre en la reforma constitucional, lo que existe es un Amparo, en cuya parte final, como un subtipo, existe el Hábeas Data para fines específicos. Igual podríamos decir de México, en donde el Amparo es el gran instrumento clásico protector de los derechos fundamentales.

Aquí se nos abre un abanico de posibilidades. El primer problema es si le damos o no el nombre de Hábeas Data. La literatura argentina recoge ese nombre, pero la Constitución no habla de Hábeas Data, con lo cual el nombre viene a ser una creación de la doctrina. Lo que existe es un Amparo que en una de sus modalidades protege a la persona frente a determinados casos, que la doctrina conoce como Hábeas Data. Pasa a ser una opción del legislador, podemos dárselo o no dárselo. Lo importante no es eso, sino lo que se protege, como veremos más adelante.

Supongamos que se acepte crear la figura; entonces el siguiente paso es ver cómo regulamos su ejercicio. Porque el grave problema que hemos tenido con varios derechos es que a la hora de protegerlos, no hemos tenido cómo hacerlo. Aquí hay dos posturas. La clásica latinoamericana en la cual a falta de reglamentación simplemente se dice que el derecho no puede ser ejercido ni defendido. Y la otra que sostiene que el derecho debe ser defendido, y si no hay una reglamentación, se debe crear una por analogía.

Es un poco lo que pasó con el Amparo de Argentina, que primero fue una creación pretoriana y luego se plasmó en la ley. Entonces, ¿cómo se regula su ejercicio? Puede no regularse y teóricamente la jurisprudencia podría configurarlo, pero esto es muy difícil en países de tradición romanista. Estos países tienden a la sumisión a la letra, a la exégesis, al código, y al texto de la ley. Esa es una herencia francesa que todavía queda, lamentablemente. Las excepciones no hacen más que confirmar la regla.

¿Cómo se regula? Puede regularse en una ley especial o en los códigos de la materia. En algunos códigos, por ejemplo en el Código Procesal Civil actual y el anterior en el Perú, se dice que en todos aquellos casos en que se controvierta un derecho legítimamente exigible y que no esté expresamente regulado, se guiarán por tal proceso que es de carácter común. Entonces uno se acomodaba a esa especie de proceso "ómnibus", al cual se subían todos aquellos que no tenían un proceso específico. 
Pero puede ser una ley especial. O los códigos o leyes generales, de acuerdo al tipo de legislación que tiene cada país. ¿Cuál de estas opciones es mejor? Vuelvo a lo anterior; ésta es una opción legislativa, aunque en América Latina tendemos a usar leyes especiales en materia de procesos constitucionales. Hay un caso notable que es Costa Rica que tiene una ley de jurisdicción constitucional (1989) y pienso que a la larga nuestros países se van a abrir a la idea de hacer códigos procesales constitucionales. El problema es que la disciplina es muy joven, muy nueva, y por eso el nombre puede parecer ambicioso.

El otro punto, el más debatible, se refiere a cuáles son los derechos que el Hábeas Data debe proteger. Quiero traer a colación algo que he visto al escuchar las opiniones de mis colegas, muy interesantes todas ellas y es lo siguiente: creo que a la hora de configurar una institución hay que darle un contenido acorde con lo que anuncia el título. En América Latina, en muchos países y el Perú entre ellos, en los años 20 y 30 operó lo que un comparatista norteamericano, Hessel Yntema, llamaba la "deformación del Hábeas Corpus". Pasó una época en el Brasil hasta el año 26 si no me equivoco, en que el Hábeas Corpus se usaba para todo y era una especie de amparo mexicano. No tan grande ni tan dimensionado, porque el Amparo mexicano es un águila, un cóndor de los Andes con alas muy desplegadas y con una cobertura inmensa.

Después vino la gran reacción, y en el Perú y en otros países de la América Latina, se ha definido y precisado la figura del Hábeas Corpus. Y es que el Hábeas Corpus en su trayectoria histórica tiene un nítido matiz de defensa de la persona, de la libertad individual. La libertad individual no solamente es el arresto, sino que es muchas cosas más. En Inglaterra hay siete modalidades de Hábeas Corpus que sirven incluso para trasladar a un preso de una Corte a otra. Hay un famoso jurista inglés es Edward Jenks, que a principios de siglo decía que el Hábeas Corpus no solamente sirve para liberar a una persona, sino para meterla en la cárcel, si bien adecuadamente, legalmente. Guarda una estructura con su nombre. El caso del Amparo es distinto, porque la palabra amparo es más comprensiva, y permite jugar con muchas cosas.

Aunque cronológicamente el primer Amparo es el mexicano, en mi opinión ha dejado de ser ya un prototipo o paradigma; es un ente deforme que se dicta en las universidades en un curso de Amparo durante 
dos años, y hay tratados de Amparo y hay abogados amparistas, porque el Amparo es todo: es casación, es Hábeas Corpus, es control de leyes, es todo. O sea, más prototipo es hoy día el Amparo sudamericano, o protección o tutela, o como lo queramos llamar.

En el caso del Hábeas Data, que es una aplicación de la figura del Hábeas Corpus, esto es "tráiganse los datos", habría que guardar correspondencia con la naturaleza del nombre y que es la protección del dato. No puede proteger todos los derechos, sino que debe limitarse a la protección de algunos derechos. El problema sería qué tipo de dato y a través de qué.

Otro punto importante es, y este es quizá el gran debate que se va a dar en Chile y se dió en el Perú en su momento y en otros países, es si el Hábeas Data debe tener o no un estatus constitucional. Vimos que la tendencia es que esté en las constituciones, que aunque son pocas y contando al cripto Hábeas Data argentino, no creo que en América Latina, aunque no los he contado, pasen de cinco los países en donde figure con su propio nombre. No digo los derechos que se defienden, que es distinto.

¿Debe o no elevarse esto a rango constitucional? Yo diría que en principio no. He tratado de buscar una explicación histórica. ¿Por qué se inicia en un país como es el Brasil y con una especie de efecto dominó empezamos a repetirlo? Ruego que disculpen la simplicidad de mi explicación, pero creo que viene un poco por la parte histórica que paso a mencionar.

Creo que podriamos dividir esta explicación en tres áreas. Uno, el mundo sajón, que es un mundo que nace al margen de la Europa continental, y que por un proceso especial se va formando un derecho común. De ahí el Common Law, porque cada príncipe o barón tenía sus propias normas, aplicadas por los jueces en los siglos XI y XII. Entonces el Derecho sajón va creciendo sobre la base de casos, como todos lo sabemos. Y naturalmente el caso lo resuelve un juez, quien es una gran figura dentro de este mundo sajón.

Hoy en día, el Derecho sajón y especialmente el de los Estados Unidos ya no es una masa caótica de datos sueltos sobre casos determinados. Hay un cierto ordenamiento; no sólo los particulares hacen sus compilaciones, sino que hay muchas leyes y códigos uniformes para toda la federación y además están los famosos re-statements, palabra casi sin traducción, que son grandes compilaciones que van sistematizando 
el Derecho y sobre todo el Derecho Privado. No obstante esto, el mundo sajón tiene en el juez a la figura fundamental. Por eso podría decirse que el mundo sajón ha vivido bajo el mito del juez.

La Europa continental no creía en el juez. Recuerden ustedes las famosas palabras de Montesquieu cuando dice que el Juez es un robot, es un autómata que pronuncia ciegamente las palabras de la ley y no puede hacer más que aplicarlas, sin siquiera mitigar su rigor. Tanto desconfía que el juez es devaluado, y tan devaluado es que en los años 20 cuando Kelsen sienta las bases doctrinarias del Tribunal Consitucional, dice en un ensayo posterior, que no podía usar el modelo de los Estados Unidos en que el Tribunal Supremo del Poder Judicial se encargaba de inaplicar las normas, con carácter de permanente, por el sistema del precedente.

No sólo desconfiaban del juez sino también de otro tipo de instituciones. Entonces crean otro órgano como es el Tribunal Constitucional, para solucionar el problema apto a la mentalidad europea. Tan bien le ha ido a Kelsen que el modelo se ha repetido y se ha difundido ampliamente. La famosa polémica con Schmitt, que fué muy incisiva, en la cual Schmitt tenía algunos puntos a favor, no tuvo eco porque el modelo calzó con la realidad.

La contrapartida ha sido la confianza casi absoluta en el legislador, una herencia rousseauniana. Mientras el sajón vivió con el mito del juez, el europeo continental vivió con el mito del legislador. Este concepto lo tomo de Carnelutti. El año 65 en Roma, Carnelutti pronunció un vibrante discurso, uno de los últimos, ya que murió a los dos años, y dijo más o menos así: el gran error de la Europa continental es haber caído en el mito del legislador y haberse olvidado del juez, que es la figura central del proceso.

Pues bien, nosotros en América Latina, aunque heredamos las ideas independentistas de los Estados Unidos, sin embargo vivimos bajo el mito del legislador en el siglo XIX. Y no pudimos creer en el juez, porque el sistema no daba para eso. El juez es importante y útil en la medida en que el sistema lo permite y el desarrollo de la población lo admite.

Pienso que frente al mito del legislador bajo el cual ha vivido Europa, y al mito del juez bajo el cual ha existido el mundo sajón, la América Latina ha pasado del mito del legislador al mito de la Constitución. Viene la obsesión por constitucionalizar todo lo que se pueda. Si 
analizamos brevísimamente las constituciones del siglo XIX en cada país, variantes más o menos, vemos que éstas van creciendo con el tiempo, y algunas son inmensas, como la de Colombia de 1991 o la del Brasil de 1988. Porque nunca confiamos en el juez, confiamos en el legislador. Pero como éste nos falló, entonces ahora confiamos en la Constitución.

Esto que es una tendencia colectiva, unida a coyunturas de orden político como es justificar golpes de Estado con constituciones, que también es otro abuso de nuestro mercado latinoamericano, hace que todo se tienda a ver recogido en la Constitución. Hay un sentimiento popular que piensa que así debe ser, porque así nos defendemos del gobierno arbitrario y autocrático.

No digo que esto sea bueno o sea malo. Quizás es malo; las constituciones nunca han resuelto nada, pero es lo que más o menos se ve. $\mathrm{Y}$ es lo que más o menos me da una explicación de lo que pasa.

La segunda parte va a ser más breve. Quiero hacer una referencia a lo que fue el debate en el Perú con respecto al Hábeas Data. El profesor Eguiguren, con el brillo que lo caracteriza, dijo cómo son las cosas y yo voy a decir qué pasó antes. En primer lugar, el Hábeas Data está constitucionalizado en la Carta de 1993. Esta Constitución se dio en virtud de que había que bautizar el golpe de Estado del Sr. Fujimori. La Carta Política del año 79 era una Constitución moderna, interesante, naturalmente con algunos errores, pero no era necesario cambiarla. La vanidad que existe mucho en la política, de perpetuarse para pasar a la historia explica esta nueva Constitución, que de paso tuvo dos objerivos: garantizar la impunidad de los golpistas de Estado, ya que la Carta del 79 era muy severa con ellos, y luego permitir la reelección inmediata del Sr. Fujimori. Como bien dicen los mejores comentaristas del 93 es una copia de la del 79. Y como siempre sucede con las copias, son malas, pues se advierten graves retrocesos.

En el caso concreto de la parte procesal que se lama "garantías constitucionales", hay cuatro de las llamadas acciones de garantía. Y de ellas, solo dos existían y eran manejables. Estaban relacionadas con los derechos humanos y eran el Hábeas Corpus y el Amparo. Ahora las hemos duplicado, y además está el Hábeas Data con todos los problemas que ha ocasionado su pésima redacción, y también la llamada Acción de Cumplimiento, que pretende hacer efectivo todo mandato legal o administrativo, que la tomaron de la Constitución colombiana y que no 
se sabe qué es. Hasta ahora nadie sabe para qué sirve. Viene la novedad $y$ vienen los problemas.

Esta Constitución se debatió de enero a setiembre del año 1993 y ya en esa época se pidió expresamente que el Hábeas Data fuese replanteado, porque tal como estaba era innecesario y rozaba con la libertad de prensa. Y eso porque el entorno político hacía temer un mal uso de esta institución, porque todo el mundo sabe que el $\mathrm{Sr}$. Fujimori está respaldado por las Fuerzas Armadas. No se sabe quién usa a quién. Y porque además el Servicio de Inteligencia fue el que suministró a la Asamblea, los primeros borradores de la Constitución, en la cual los delitos a través de la prensa se ventilaban en el fuero militar.

Cuando es aprobado el borrador y puesto a debate, la gente empieza a sospechar de la configuración del Hábeas Data y pide su modificación. En el diario "El Comercio", el más importante del país, meses antes que fuese promulgada la Constitución en forma, la oposición pide la reformulación del Hábeas Data. El título dice así: "Oficialismo no admitió a debate pedido de eliminación de Recurso de Hábeas Data", y en su subtítulo, "Pese a fundamentaciones sobre amenaza a la libertad de prensa". Pero no hicieron caso y siguieron tercamente hasta el final.

Antes de promulgarse la Constitución, hubo un congreso de Derecho Constitucional en la Universidad de Lima (setiembre de 1993), y entre los invitados extranjeros estaba nuestro amigo Néstor P. Sagüés quien advirtió: "Esto es riesgoso". Al costado estaba el presidente de la Comisión de Constitución, quien no se inmutó con la crítica.

La Constitución fue sometida a referéndum; los datos oficiales dicen $52 \%$ a favor, $48 \%$ en contra. Ése fue el dictum popular. Para efectos legales, la Constitución fue aprobada. Pero ¡caramba!, por qué márgenes; y muy estrechos.

El oficialismo bajó su vanidad, y como la prensa seguía bombardeando por esta nueva configuración, el Gobierno tuvo que ceder y consensuadamente se eliminó de la figura del Hábeas Data aquella parte que representaba una amenaza a los medios de prensa. Ésa fue la primera reforma que se hizo a la Constitución; o sea, para dar marcha atrás en aquello en que se había detectado un error.

Sobre el Hábeas Data en la Constitución peruana, como lo dijo Eguiguren, yo creo que era innecesario, que el Amparo perfectamente 
podía cubrirlo. Pero también los académicos debemos ser un poco prácticos. La figura como que ha calado, gusta, es agradable. A la gente le agrada tener un instrumento fácil para modificar el dato que hay en la computadora del vecino o de un ente público determinado. Por eso pienso que va a quedar, y que la Constitución en este punto, va a sufrir modificaciones parciales para redimensionar la figura del Hábeas Data y limarle sus asperezas. 